\title{
TECNOLOGIAS DIGITAIS E METODOLOGIAS ATIVAS: QUAIS SÃO CONHECIDAS PELOS PROFESSORES E QUAIS SÃO POSSÍVEIS NA EDUCAÇÃO?
}

\author{
DIGITAL TECHNOLOGIES AND ACTIVE METHODOLOGIES: \\ WHICH ARE KNOWN TO TEACHERS AND WHICH ARE POSSIBLE IN EDUCATION? \\ BRUNO SILVA LEITE ${ }^{1}$
}

\section{RESUMO}

As metodologias ativas e as tecnologias digitais na Educação estão cada vez mais presentes em sala de aula. As metodologias ativas são estratégias que colocam os estudantes como principais agentes de seu aprendizado, já as tecnologias digitais auxiliam nas práticas pedagógicas. Nesse contexto, esta pesquisa apresenta um levantamento realizado com 948 professores de diversas áreas do conhecimento, sobre quais tecnologias digitais e metodologias ativas são conhecidas por eles e quais aplicativos podem ser utilizados com alguma metodologia ativa na educação relacionando com a aprendizagem tecnológica ativa. Os resultados mostram que a metodologia ativa mais conhecida pelos professores é a aprendizagem baseada em problemas seguida da aprendizagem baseada em projetos. Já em relação ao aplicativo mais conhecido pelos professores os resultados apontam para os aplicativos da Google for education, o Quizizz e o Kahoot!. Ademais, os professores consideraram que estes três aplicativos são os mais indicados para serem utilizados na Educação.

Palavras-chave: Metodologias Ativas. Tecnologias Digitais. Aprendizagem Tecnológica Ativa. Aplicativos na Educação.

\section{ABSTRACT}

Active methodologies and digital technologies in Education are increasingly present in the classroom. Active methodologies are strategies that put students as the main agents of their learning, while digital technologies assist in pedagogical practices. In this context, this research presents a survey carried out with 948 teachers from different areas of knowledge, about which digital technologies and active methodologies are known to them, and which applications can be used with some active methodology in education relating to active technological learning. The results show that the active methodology best known by teachers is problem-based learning followed by project-based learning. Regarding the application best known by teachers, the results point to Google for education applications, Quizizz, and Kahoot!. In addition, teachers considered that these three applications are the most suitable for use in Education.

Keywords: Active Methodologies. Digital Technologies. Active Technological Learning. Applications in Education.

\section{RESUMEN}

Las metodologías activas y las tecnologías digitales en Educación están cada vez más presentes en el aula. Las metodologías activas son estrategias que colocan a los estudiantes como los principales agentes de su aprendizaje, mientras que las tecnologías digitales asisten en las prácticas pedagógicas. En este contexto, esta investigación presenta una encuesta realizada a 948 docentes de diferentes áreas del conocimiento, sobre qué tecnologías digitales y metodologías activas son conocidas por ellos y qué aplicaciones pueden ser utilizadas con alguna metodología activa en educación relacionada con el aprendizaje tecnológico activo. Los resultados muestran que la metodología activa más conocida por los profesores es el aprendizaje basado en problemas seguido del aprendizaje basado en

1 Doutor em Química pela Universidade Federal de Pernambuco. Docente do Departamento de Educação da Universidade Federal Rural de Pernambuco. E-mail: brunoleite@ufrpe.br. Orcid: http://orcid.org/0000-0002-9402-936X. 
proyectos. Respecto a la aplicación más conocida por los profesores, los resultados apuntan a las aplicaciones de Google para educación, Quizizz y Kahoot!. Además, Ios profesores consideraron que estas tres aplicaciones son las más adecuadas para su uso en Educación.

Palabras-clave: Metodologías Activas. Tecnologías Digitales. Aprendizaje Tecnológico Activo. Aplicaciones en Educación.

\section{CONSIDERAÇÕES INICIAIS}

A integração das Tecnologias Digitais de Informação e Comunicação (TDIC) na Educação tem crescido nos últimos anos. As tecnologias digitais potencializam as interações entre professor-estudante, professor-professor, estudante-estudante, criando novos espaços de aprendizagens, uma vez que elas (as tecnologias) estão cada vez mais comuns nos ambientes educacionais. Segundo Reis, Leite e Leão (2017), 0 uso das tecnologias tem possibilitado o acesso a uma educação diferenciada considerando que sua inserção nas escolas é um fenômeno em franca expansão. Todavia, a construção de conhecimentos apropriados à utilização adequada das TDIC no contexto educacional, por vezes, são considerados como entraves a serem superados pelos educadores.

0 impacto das TDIC no cotidiano das pessoas e na Educação, tem representando um grande desafio que, concomitantemente, suscita novas oportunidades para a elaboração de estratégias de ensino e novas possibilidades de aprendizagem. A inserção das tecnologias digitais na Educação pode propiciar maior flexibilidade de tempo e espaço, tornando 0 acesso aos materiais compartilhados pelos professores possíveis a qualquer momento e em qualquer lugar, desde que tenha acesso a Internet (BOTTENTUIT JÚNIOR, 2012; ROCHA; BITTAR, 2017; GRILLO; AHLERT, 2018).

As tecnologias digitais têm transformado as práticas tradicionais da educação fazendo uso, em alguns casos, de inovações que têm modificado as formas de significação e interpretação. Por outro lado, não se deve cair no encantamento de que 0 uso de uma determinada tecnologia ou sistema por si só aumentará seu desempenho no trabalho, na escola ou em qualquer outro ambiente. Entende-se que, as tecnologias e seus aplicativos por si só não trarão mudanças efetivas, se não vierem acompanhadas de propostas metodológicas que valorizam a construção do conhecimento e de sua importância na realidade social do estudante.

Desse modo, as mudanças nas práticas pedagógicas têm sido cada vez mais complexas quando envolvem uma "Educação Digital". 0 professor, nesse contexto, tem o desafio de se apropriar de recursos didáticos digitais e utilizá-los no processo de ensino e aprendizagem de forma inovadora. Contudo, a inovação na Educação vai além da incorporação das tecnologias digitais, ela também se relaciona com abordagens centradas no estudante, ou seja, abordagens que fazem uso de metodologias ativas (PAIVA; PARENTE; BRANDÃO; QUEIROZ, 2016; DIESEL; BALDEZ; MARTINS, 2017; GRILLO; AHLERT, 2018).

0 professor ao utilizar as tecnologias digitais, em especial os aplicativos digitais, com seus estudantes deve ensinar a selecionar, analisar, criticar, comparar, avaliar, sintetizar, comunicar e informar. Esses são processos de pensamento complexos que o professor mediador deve realizar, para que seus estudantes construam seu conhecimento. Destarte, quando o professor se torna mediador e 0 estudante responsável pela construção de seu conhecimento, observa-se as características presentes nas metodologias ativas.

Nesse sentido, esta pesquisa teve como objetivo investigar quais metodologias ativas e aplicativos digitais são conhecidos por professores de distintas áreas do conhecimento do ensino básico 
e superior. Ademais, a pesquisa também analisa quais aplicativos na opinião destes professores podem ser utilizados com alguma metodologia ativa na educação e se este uso pode envolver os pressupostos da aprendizagem tecnológica ativa.

\section{TECNOLOGIAS DIGITAIS}

As tecnologias estão sendo cada vez mais integradas aos ambientes de ensino com o objetivo de aumentar 0 envolvimento e a motivação dos estudantes. Segundo Reis et al. (2017), pesquisas realizadas no Brasil tem mostrado que as tecnologias estão ganhando mais espaço e estão mais próximas da população. A tecnologia digital é atualmente o maior meio no qual a informação, a comunicação e a aquisição de conhecimento estão sendo produzidos. Contudo, para a efetividade do uso das TDIC no ensino, há necessidade de qualificação e formação contínua dos professores, para que o uso delas tenha objetivo específico e a aplicação seja horizontal. Na visão de Lucena (2016, p. 286), é perceptível que na maioria dos "cursos de formação inicial de professores, [...], as tecnologias não estão inseridas no currículo". Garantir uma formação no uso das TDIC se mostra necessário para melhoria da Educação.

É preciso entender que as tecnologias digitais são mais do que recursos auxiliares, elas apresentam condições para o desenvolvimento do ensino, dando liberdade e democratização a informação e a construção do conhecimento. As tecnologias podem proporcionar facilidades no meio educacional se considerar que 0 uso destas podem contribuir para novas práticas pedagógicas, permitindo 0 surgimento de diferentes perspectivas educacionais, provocando mudanças significativas na forma de ensinar e aprender (ARAUJO, 2020; LEITE, 2020). Nesse contexto, as tecnologias digitais têm transformado as práticas tradicionais da Educação fazendo uso, por exemplo, da aprendizagem móvel (Mobile learning), que consiste na incorporação de dispositivos móveis no processo de ensino e aprendizagem, podendo ajudar a potencializar experiências de aprendizagens presenciais.

Os dispositivos móveis, em especial os smartphones e tablets, podem auxiliar no processo de ensino e aprendizagem na Educação, ao contribuírem para (re)construção de ações oportunas para a construção do conhecimento. Segundo Araujo (2020, p. 69), a "expansão e popularização das tecnologias móveis proporcionou um notável desenvolvimento de softwares para dispositivos móveis: os aplicativos". Estes aplicativos possuem amplas características que os incrementam: como os valores financeiros dos aplicativos, em que sua maioria é baixado de graça nas plataformas específicas; são de fácil instalação, além de funcionarem em diversos smartphones; podem ser baixados em pouco tempo. Os dispositivos móveis possuem funções diversas e os aplicativos que podem ser instalados dão condições para as inúmeras possibilidades.

Os aplicativos fazem parte do cotidiano da sociedade, integrando variados setores (comunicação, lazer, economia, saúde etc.), com isso podem e devem fazer parte do processo de ensino e aprendizagem. 0 uso de aplicativos para o ensino é muito dinâmico, pois muitos são jogos, redes sociais, quiz, além de ter dispositivos direcionados aos estudos, como e-books, manuais, simuladores, dentre outras possibilidades (BOTTENTUIT JÚNIOR, 2012; LEITE, 2014; LUCENA, 2016; ARAUJO, 2020). Todavia, é pujante assegurar que os aplicativos não têm e nem devem ter o objetivo de substituir os professores, os livros ou os materiais didáticos, mas de auxiliarem na transposição de obstáculos da aprendizagem, como a acessibilidade e liberdade, pois quanto maior 0 auxílio, maior a chance da construção do conhecimento. Ademais, os aplicativos são atrativos que podem promover engajamento maior dos estudantes em seus estudos. Com os dispositivos móveis, os estudantes têm a possibilidade de estarem conectados a qualquer momento, proporcionando autonomia e protagonismo a eles. 
Defende-se que o desenvolvimento de aplicativos para o ensino seja realizado por meio de uma equipe multidisciplinar auxiliando no aprimoramento destes aplicativos, em que cada parte contribui com sua área de conhecimento. Os aplicativos devem oferecer opções para construção de situações didáticas diferenciadas. Além disso, em relação à produção de um aplicativo com fins pedagógicos, deve-se levar em consideração as necessidades específicas de cada material a ser produzido, 0 que pode tornar esse mecanismo eficiente. 0 uso de aplicativos na Educação não se deve apenas a sua atratividade apresentada em seus layouts, mas deve ocorrer principalmente por serem recursos que fazem parte dos hábitos socioculturais. Com 0 uso de aplicativos na Educação o professor pode se tornar um agente mediador do ensino, haja vista que este tipo de recurso permite maior protagonismo dos estudantes, possibilitando uma prática fundamentada nos preceitos das metodologias ativas.

\section{METODOLOGIAS ATIVAS}

Compreender que uma determinada metodologia de ensino envolve a relação entre 0 ambiente educacional, cultural e a sociedade, contribui para diferentes ações dos atores envolvidos no processo de ensino e aprendizagem. As diversas matrizes pedagógica-metodológicas (escola nova, pedagógica libertadora, pedagogia histórico-crítica) contribuíram para o que atualmente é denominado de metodologias ativas, quer seja pela ruptura de métodos que ignoram o papel do estudante no processo de ensino e aprendizagem, quer seja nas metodologias que valorizam o estudante como participativo e crítico dentro da sociedade. Talvez, seja por isso que Leite (2018) já dizia que as metodologias ativas não são novidades.

As metodologias ativas têm sua base na Escola Nova, mas resgata os pressupostos presentes na pedagogia libertadora e na pedagogia histórico-crítica. Elas têm buscado refletir sobre o papel do professor e do estudante nos processos de ensino e aprendizagem, procurando promover mudanças nas práticas em sala de aula que estão, por muitas vezes, enraizadas no modelo tradicional de ensino. Para Berbel (2011, p. 29) as metodologias ativas se baseiam em formas de "desenvolver o processo de aprender, utilizando experiências reais ou simuladas, visando às condições de solucionar, com sucesso, desafios advindos das atividades essenciais da prática social, em diferentes contextos". As metodologias ativas "possibilitam a valorização da formação crítica e reflexiva do estudante que participa da construção de seu conhecimento, no processo de ensino e aprendizagem, favorecendo sua autonomia" (LEITE, 2017a, p. 1). São processos interativos de conhecimento, análise, estudos, pesquisas e decisões que podem ser individuais ou coletivas com 0 objetivo de encontrar soluções para um determinado problema (BERBEL, 2011; DIESEL et al., 2017; LEITE, 2020).

Ao enfatizar o papel protagonista do estudante, as metodologias ativas consideram 0 envolvimento reflexivo, participativo e direto dos estudantes em todas as etapas que envolvem sua aprendizagem, em que eles experimentam, desenham e criam com a mediação do professor, isto é, os estudantes se tornam os principais agentes de seu aprendizado. Ademais, a ideia de metodologia ativa, para Diesel e colaboradores (2017), está situada como uma possibilidade de deslocamento da perspectiva do docente (ensino) para 0 estudante (aprendizagem), visando estimular a autoaprendizagem e a curiosidade do estudante para pesquisar, refletir e analisar possíveis situações na tomada de decisão. Considerando uma maior participação do estudante no processo de construção do seu conhecimento, o estudante passa a ter mais controle do que está sendo discutido em sala de aula, já que possibilita que ele realize diferentes ações e construções mentais (DIESEL et al., 2017). 
Paiva e colaboradores (2016), identificaram diferentes modelos e estratégias para a operacionalização das metodologias ativas na Educação. Segundo os autores, há diferentes alternativas para o processo de ensino e aprendizagem, com diversos benefícios e desafios, nos diferentes níveis educacionais. Algumas destas metodologias são: aprendizagem baseada em problemas/projeto/jogos, instrução por pares, estudo de caso (método do caso), ensino sob medida, gamificação, método POE (Previsão, Observação e Explicação), sala de aula invertida, aprendizagem pela pesquisa, pensamento compartilhado em pares, aprendizagem maker, Design Thinking, rotação por estações etc. Nesse contexto, o modelo da Aprendizagem Tecnológica Ativa parece ser adequado ao contemplar os processos inerentes em uma aprendizagem ativa fazendo uso das tecnologias digitais.

\section{APRENDIZAGEM TECNOLÓGICA ATIVA}

As discussões que norteiam a propagação das TDIC por meio das metodologias ativas na educação básica e superior se baseiam em paradigmas pré-estabelecidos para sistematização de novas práticas pedagógicas de ensino que, proponham o desuso progressivo do método tradicional de ensino, e oportunize a incorporação de recursos didáticos contemporâneos (computadores, tablets, smartphones etc.) como recursos auxiliadores na construção de conhecimento.

Com surgimento de práticas pedagógicas que fazem uso das tecnologias digitais por meio de estratégias fundamentadas nas metodologias ativas, o modelo da Aprendizagem Tecnológica Ativa (ATA) descreve como ocorre o processo de ensino e aprendizagem quando estes dois ambientes são utilizados de forma conjunta. 0 modelo da ATA destaca a estreita relação entre 0 uso de metodologias ativas com variados tipos de tecnologias digitais propondo que 0 indivíduo tenha controle de sua aprendizagem, acessando conteúdos digitais a qualquer momento, em qualquer lugar, em vez de depender exclusivamente do professor para seguir instruções (LEITE, 2020).

Se a tecnologia pode ser útil no processo de ensino e aprendizagem, tem-se então que o professor é figura essencial nesse processo, pois se ele não souber trabalhar de forma efetiva em um ambiente de aprendizagem equipado com tecnologia, o equipamento por si só não trará benefício algum. Saber escolher e utilizar as tecnologias digitais em uma aprendizagem tecnológica ativa é um dos papéis do professor (LEITE, 2018). De modo igual, as metodologias ativas apontam para o papel importante do ensino centrado no estudante, uma vez que o torna autônomo, crítico, reflexivo etc., promovendo seu protagonismo.

A aprendizagem tecnológica ativa se baseia em abordagens construtivista, construcionista e conectivista e enfatiza cinco pilares que possibilitam que o processo de ensino e aprendizagem ocorra de forma ativa utilizando as tecnologias digitais (LEITE, 2018). Cada pilar da ATA destaca ações durante o processo de construção do conhecimento:

- $\quad 1^{0}$ Pilar (Papel Docente): em que o professor atua como mediador/orientador/facilitador do conhecimento a ser construído em sala de aula. 0 professor deve despertar no estudante 0 desejo de se apropriar de outros conhecimentos que ainda não possui;

- $\quad 2^{0}$ pilar (Protagonismo do Estudante): possibilita que 0 estudante aprenda de forma personalizada e por competências. 0 conhecimento é construído quando 0 estudante participa ativamente, buscando conhecer e, assim, experimentando, pesquisando, refletindo etc.;

- $\quad 3^{0}$ pilar (Suporte das Tecnologias): a escolha dos recursos tecnológicos irá contribuir para a aprendizagem tecnológica ativa possibilitando a criação de novos caminhos para 
a aprendizagem. Deve-se considerar a escolha consciente da tecnologia digital que melhor se adapta ao conteúdo a ser ensinado/aprendido;

- $\quad 4^{0}$ pilar (Aprendizagem): diz respeito as várias aprendizagens que podem ocorrer em uma atividade de ensino, quatro tipos de aprendizagens (individual, colaborativa, social e ubíqua - todas fundamentadas na aprendizagem ativa) são mais comuns na ATA, mas não são as únicas. Destaca-se que a aprendizagem ativa ocorre quando 0 estudante interage com 0 assunto a ser ensinado (ouvindo, falando, perguntando, discutindo, fazendo e ensinando), em que ele é estimulado a construir o conhecimento ao invés de recebê-lo de forma passiva do professor, podendo fornecer uma aprendizagem mais envolvente e eficiente;

- $\quad \mathbf{5}^{\mathbf{0}}$ pilar (Avaliação): 0 professor, dentro de uma atividade envolvendo a ATA, irá definir a avaliação a ser utilizada, considerando que há diversos tipos de avaliação que podem ser observadas (diagnóstica, formativa, somativa, autoavaliação, classificatória etc.) podendo ocorrer de maneira formal ou informal.

Cada característica supracitada constitui um dos pilares da ATA (LEITE, 2018) e essas características explicam como pode ocorrer o processo de ensino e aprendizagem, principalmente quando se envolvem o protagonismo do estudante e as metodologias ativas incorporadas às tecnologias digitais. Ademais, é interessante notar que a aprendizagem tecnológica ativa possibilita caminhos para uma aprendizagem centrada nos estudantes, permitindo que o professor acompanhe o processo de construção do conhecimento destes atuando como orientador, supervisor e facilitador do processo de aprendizagem.

\section{PERCURSO METODOLÓGICO}

Esta pesquisa trata de um estudo descritivo, de caráter exploratório, que busca conhecer quais metodologias ativas e aplicativos digitais são conhecidas por professores do ensino básico e superior. Além de investigar quais aplicativos podem ser utilizados com alguma metodologia ativa na educação e se podem envolver os pressupostos da aprendizagem tecnológica ativa. Por caracterizar-se como um estudo exploratório, a pesquisa faz uso de métodos qualitativos. Na percepção de Gil (2017), as pesquisas exploratórias procuram obter uma visão geral, de modo aproximado, de determinado fato. Elas "têm como propósito proporcionar maior familiaridade com o problema, com vistas a torná-lo mais explícito" (GIL, 2017, p. 26), neste caso, as metodologias ativas e tecnologias digitais conhecidas pelos professores.

As ações foram delineadas por meio de uma pesquisa de levantamento que se caracteriza pela "interrogação direta das pessoas cujo comportamento se deseja conhecer" (GIL, 2017, p. 33), proporcionando informações gerais sobre determinado grupo. Assim, o trabalho foi dividido em duas etapas:

A primeira etapa se constitui da elaboração e disponibilização do questionário investigativo. Segundo Gil (2017, p. 95), a "elaboração do questionário consiste basicamente em traduzir os objetivos específicos da pesquisa", neste caso, quais tecnologias digitais e metodologias ativas são conhecidas pelos professores do ensino básico e superior. 0 questionário foi dividido em duas partes e versava sobre informações gerais dos participantes da pesquisa (primeira parte) e sobre o conhecimento em relação aos aplicativos digitais que podem ser utilizados a partir de práticas envolvendo 
metodologias ativas (segunda parte). 0 questionário foi elaborado no formulário do Google contendo 19 perguntas (13 perguntas fechadas e 6 perguntas abertas), conforme observado no Quadro 1, e foi disponibilizado nas redes sociais (Facebook, instagram, twitter etc.), além de ser compartilhado em páginas de programas de pós-graduação e por e-mail. 0 questionário ficou disponível no final do primeiro semestre de 2020 por 45 dias consecutivos, tendo a divulgação ocorrendo em três momentos (a cada 15 dias a divulgação era reforçada nos ambientes virtuais com novas postagens e envios).

Quadro 1 - Perguntas do Questionário investigativo.

\begin{tabular}{|c|l|}
\hline Questão & \\
\hline 1 & Identificação \\
\hline 2 & Se professor, qual sua área de formação? \\
\hline 3 & Em qual unidade federativa você atua profissionalmente? \\
\hline 4 & Qual sua faixa etária? \\
\hline 5 & Qual seu grau de instrução? \\
\hline 6 & Fez alguma pós-graduação envolvendo Tecnologias na Educação? \\
\hline 7 & Há quanto tempo você leciona? \\
\hline 8 & Qual(is) nível(is) você leciona? \\
\hline 9 & Atua em qual(ais) rede(s) de ensino? \\
\hline 10 & Você já utilizou alguma tecnologia digital para ensinar? \\
\hline 11 & $\begin{array}{l}\text { Se sim, o uso fez diferença em sua prática pedagógica? } \\
\text { Comente um pouco }\end{array}$ \\
\hline 12 & $\begin{array}{l}\text { Se não, você acha que faria diferença em sua prática pedagógica? } \\
\text { Comente um pouco }\end{array}$ \\
\hline 13 & Você já ouviu falar em Metodologias Ativas? \\
\hline 14 & $\begin{array}{l}\text { Qual(is) metodologia(s) ativa(s) você conhece? } \\
\text { É possível marcar mais de uma opção }\end{array}$ \\
\hline 15 & $\begin{array}{l}\text { Dos aplicativos abaixo quais você acredita que podem ser utilizados com alguma metodologia ativa? } \\
\text { É possível marcar mais de uma opção }\end{array}$ \\
\hline 16 & $\begin{array}{l}\text { Quais dos aplicativos abaixo você não conhece? } \\
\text { É possível marcar mais de uma opção }\end{array}$ \\
\hline 17 & $\begin{array}{l}\text { Quais aplicativos você conhece e que podem ser utilizados dentro de uma abordagem baseada em } \\
\text { metodologias ativas e não foram citados aqui? }\end{array}$ \\
\hline 18 & Indique três aplicativos que você considera importante de ser utilizado na Educação. \\
\hline & Se desejar, deixe um comentário \\
\hline 19
\end{tabular}

Fonte: Elaborado pelo autor.

Na segunda etapa realizou-se a análise dos dados coletados no formulário. Os registros dos questionários foram feitos diretamente no Google Formulários e sistematizados e analisados no programa Microsoft Exce/®. Ao todo foram coletadas respostas de 1072 participantes. Como 0 objetivo proposto era analisar as impressões dos professores, após o refinamento, 948 respostas dos participantes (apenas professores) foram analisadas. A análise das respostas do questionário investigativo seguiu um processo quanti-qualitativo, aferindo, interpretando e

2 A relação das metodologias ativas estão na Tabela 2.

3 A relação dos aplicativos estão na Tabela 3.

4 A relação dos aplicativos estão na Tabela 3. 
organizando as respostas de modo estatístico, possibilitando inferir os dados transformando em informações, expondo de maneira ordinária (CARM0, 2013). Ademais, considera-se que as respostas obtidas no questionário foram suficientes e satisfizeram o número necessário para a coleta, e posteriores conclusões.

Durante a coleta dos dados, não foram solicitadas informações que pudessem identificar os participantes, mantendo o anonimato destes. Assim, procedeu-se a atribuição do código PN para representar a fala/resposta do participante, em que $\mathrm{P}$ significa participante e $\mathrm{N} 0$ número de sua resposta no questionário, sendo $\mathrm{N}=1,2,3, \ldots 948$.

\section{RESULTADOS E DISCUSSÃO}

Nesta seção, apresenta-se os resultados obtidos no questionário investigativo e algumas implicações são destacadas. Devido à grande quantidade de textos produzidos pelos professores nas questões abertas do questionário, optou-se por reproduzir apenas algumas respostas buscando explicitar como se deu o processo. Além disso, foram mantidos os textos conforme escrito pelos professores.

Na primeira parte do questionário (Questões de 1 a 9), dos 948 participantes, haviam 940 professores em exercício, dois diretores escolares, um coordenador pedagógico e cinco estudantes. Ressalta-se que todos estes também são professores, tanto os gestores como os que se identificaram como estudantes (pois são professores que estão como estudantes de pós-graduação). Ao serem questionados sobre sua área de formação (Questão 2), os resultados observados foram diversos, no grupo dos respondentes haviam professores de Português, Matemática, Química, Física, Biologia, História, Geografia, além de pedagogos, professores de direito, medicina, música, dentre outras áreas. Já em relação ao local em que eles atuam profissionalmente (Questão 3), os dados são descritos na Tabela 1.

Observa-se que durante o período da pesquisa apenas o Amapá não teve participação de nenhum professor, embora o formulário tenha sido divulgado em grupos que há professores deste estado e de alguns programas de pós-graduação da região. Além disso, participaram professores de Portugal (cinco), Angola (um), Colômbia (um) e Argentina (um).

Em relação à faixa etária (Questão 4), boa parte dos professores estão na faixa de idade de 30 a 39 anos (38\%), seguido das idades entre 40 a 50 anos (32,9\%), 51 a 60 anos (14,1\%), 18 a 29 anos (11,4\%) e a menor parcela, professores acima de 60 anos (3,6\%). No que diz respeito ao grau de instrução destes professores (Questão 5) o Gráfico 1 apresenta os dados obtidos. É preciso destacar que alguns destes professores ainda não são/estão formados oficialmente, indicando possíveis problemas oriundos da formação inicial, dentre eles, terem que atuar enquanto estão em formação (GUEDES; SANCHEZ, 2017; ROCHA; BITTAR, 2017; CÓSSIO, 2018; SILVA NETO; LEITE, 2020). 
Tabela 1 - Regiões de atuação dos respondentes.

\begin{tabular}{lcc}
\hline \multicolumn{1}{c}{ Local } & Quantidade & $\%$ \\
\hline ACRE (AC) & 2 & $0,21 \%$ \\
\hline ALAGOAS (AL) & 14 & $1,48 \%$ \\
\hline AMAZONAS (AM) & 14 & $1,48 \%$ \\
\hline BAHIA (BA) & 14 & $1,48 \%$ \\
\hline CEARÁ (CE) & 16 & $1,69 \%$ \\
\hline DISTRITO FEDERAL (DF) & 46 & $4,85 \%$ \\
\hline ESPÍRITO SANTO (ES) & 12 & $1,27 \%$ \\
\hline GOIÁS (GO) & 82 & $8,65 \%$ \\
\hline MARANHÃO (MA) & 4 & $0,42 \%$ \\
\hline MATO GROSSO (MT) & 20 & $2,11 \%$ \\
\hline MATO GROSSO DO SUL (MS) & 6 & $0,63 \%$ \\
\hline MINAS GERAIS (MG) & 124 & $13,08 \%$ \\
\hline PARÁ (PA) & 12 & $1,27 \%$ \\
\hline PARAÍBA (PB) & 74 & $7,81 \%$ \\
\hline PARANÁ (PR) & 44 & $4,64 \%$ \\
\hline PERNAMBUCO (PE) & 110 & $11,60 \%$ \\
\hline RIO DE JANEIRO (RJ) & 66 & $6,96 \%$ \\
\hline RIO GRANDE DO NORTE (RN) & 22 & $2,32 \%$ \\
\hline RIO GRANDE DO SUL (RS) & 104 & $10,97 \%$ \\
\hline RONDÔNIA (RO) & 8 & $0,84 \%$ \\
\hline RORAIMA (RR) & 2 & $0,21 \%$ \\
\hline SANTA CATARINA (SC) & 24 & $2,53 \%$ \\
\hline SÃO PAULO (SP) & 96 & $10,13 \%$ \\
\hline SERGIPE (SE) & 16 & $1,69 \%$ \\
\hline TOCANTINS (TO) & 4 & $0,42 \%$ \\
\hline Atuo fora do País & 8 & $0,84 \%$ \\
\hline Não atUO & 4 & $0,42 \%$ \\
\hline
\end{tabular}

Fonte: Elaborado pelo autor.

Gráfico 1 - Grau de instrução dos participantes.

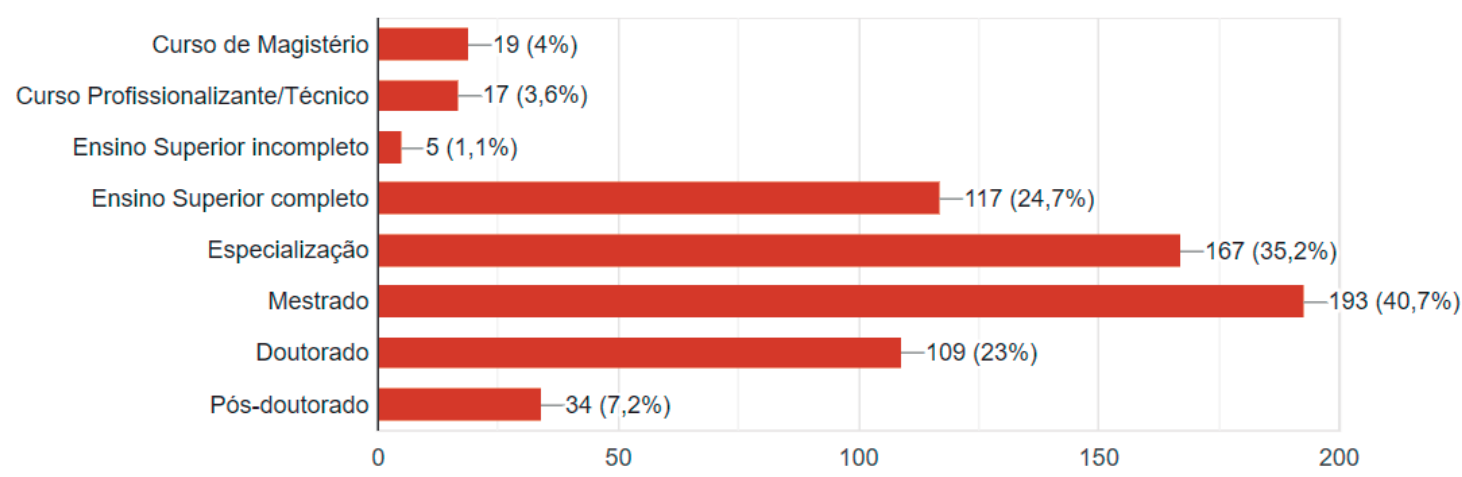

Fonte: Elaborado pelo autor. 
Dos participantes, 69\% deles fizeram algum tipo de pós-graduação envolvendo Tecnologias na Educação (Questão 6). Belloni (1998), já alertava sobre as novas tendências na formação de professores, dentre elas a formação de professores com tecnologias, que para a autora "resultará em aumento de produtividade dos sistemas e, portanto, a médio e longo prazo significará maior rentabilidade, evitando não só o desperdício com o fracasso escolar, como as frustrações decorrentes dele e da inadequação às demandas sociais" (BELLONI, 1998, sp.). Tal perspectiva se mantém atual, pois na visão de Júnior (2018), as recomendações dos órgãos internacionais para formação e/ou capacitação de professores, atribuem às tecnologias a solução dos problemas educacionais. Contudo, é preciso cuidado com o encantamento das tecnologias na Educação, se sua incorporação não vier acompanhada de novas práticas pedagógicas, em nada estas tecnologias irão ajudar a diminuir os problemas educacionais.

Em relação ao tempo de atuação (Questão 7), 34\% lecionam entre onze e vinte anos, seguido de $26 \%$ que atuam há mais de vinte anos e de $22 \%$ que ministram aulas entre seis e dez anos. Os que atuam entre dois e cinco anos configuram $12 \%$ do total e há um ano representam $6 \%$ do total de participantes. Já em relação aos níveis de ensino que lecionam (Questão 8), os dados revelam que a maioria atua no ensino médio (47,5\%), seguido do ensino superior com uma diferença pequena $(44,5 \%)$ e $39,7 \%$ ministram aulas no ensino fundamental. Na pós-graduação e no ensino profissionalizante 0 percentual fica abaixo dos $22 \%$. E finalizando a primeira parte do questionário, observa-se que $46,3 \%$ dos professores que participaram da pesquisa são da rede estadual de ensino. Os demais professores são da rede particular $(34,9 \%)$, rede de ensino federal $(24,9 \%)$ e da esfera municipal (17,8\%). Destaca-se que nesta questão (Qual(is) nível(is) você leciona?) era possível aos docentes responderem mais de uma opção.

Na segunda parte dos resultados da pesquisa, em que se buscou analisar o conhecimento dos participantes em relação aos aplicativos digitais que podem ser utilizados a partir de práticas envolvendo metodologias ativas e as tecnologias digitais (na perspectiva da ATA), os dados revelam que $91,8 \%$ dos professores (870 ao todo) já utilizaram alguma tecnologia para ensinar (Questão 10). Nesse contexto, Lucena (2016) aponta que as tecnologias por fazerem parte do dia a dia de muitas pessoas, os professores ao interagirem com elas, estão reestruturando a forma que ensinam. Já para Araujo (2020), o uso dos dispositivos móveis na educação pode promover mudança dos processos de ensino, como a personalização da aprendizagem e a emancipação do estudante.

Para os 870 professores que afirmaram já terem utilizados alguma tecnologia em sua prática pedagógica (Questão 10) foi solicitado que estes comentassem como foi essa experiência e se 0 uso fez diferença em sua prática pedagógica (Questão 11). Os resultados mostram que para 1,8\% (8 professores) não houve diferença. Algumas respostas foram: "Não fez diferença. 0 uso do Moodle não ajudou muito devido ao fato de que nem todos os alunos têm acesso à internet, e houve falta de interesse por parte de alguns" (P136), "Não muito. Pouquíssimos alunos assistiram aos vídeos na plataforma digital e não tive o cuidado de fazer nenhum tipo de medição e/ou observação atenta" (P812) e "Não consegui devido a muitas dificuldades que os alunos impõe (P849)" (neste caso, 0 professor não explicitou quais dificuldades eram). Observa-se que estas falas reforçam discussões atuais presentes na literatura sobre o uso das tecnologias na educação, quer seja por limitação técnica/tecnologia, por limitação pedagógica (falta de capacitação dos professores) ou por desinteresse dos envolvidos (PRETTO; PASSOS, 2017; ROCHA; BITTAR, 2017; REIS et al., 2017). Por outro lado, $98,2 \%$ (dos 870 considerados nesta resposta, isto é, 862 professores) relataram que 0 uso das tecnologias contribuiu para o processo de ensino e aprendizagem, conforme se observa em algumas 
respostas a seguir: "Não só fez diferença como despertou nos outros professores interesses e até mesmo mudanças em suas práticas também. Você tem alunos e colegas professores motivados e interessados em novas práticas" (P788) e "Entendo que sim. A compreensão dos alunos em termos abstratos foi melhorada a partir do uso de simulações computacionais quando comparado ao uso de outros materiais ou apenas com a explicação no quadro" (P361). Um dos professores (P427) sintetizou a sua experiência relacionando as tecnologias digitais com as metodologias ativas, ou seja, apresentando os pressupostos da aprendizagem tecnológica ativa (LEITE, 2018), para ele

Qualquer tecnologia é importante quando colocamos a aprendizagem do aluno na centralidade do processo ensino-aprendizagem. Desse modo, considerando uma cultura digital que determina e é determinada pelas práticas sociais, nós professores não podemos prescindir de nos valermos, também, das tecnologias digitais em nossas práticas pedagógicas que se queira, verdadeiramente, ativa (P427).

Essas respostas corroboram com diversas pesquisas (BOTTENTUIT JÚNIOR, 2012; LEITE, 2014; LUCENA, 2016; ARAUJO, 2020) que apontam que o uso das tecnologias digitais contribuem para o processo de construção de conhecimento. Outra resposta que chama a atenção para refletir sobre 0 uso das tecnologias no ensino de qualquer disciplina curricular é apontada pelo professor P72, segundo ele

0 uso de TDIC fez com que eu refletisse mais sobre 0 aprendizado dos aluno(a)s buscando estratégias para proporcionar o seu engajamento e protagonismo. Tive que estudar muito para conhecer e me apropriar de algumas TDIC, o que acho normal e um ponto muito positivo da profissão docente, ou seja, estamos sempre em formação devido à nossa incompletude (P72).

Este professor (P72) destaca a importância da formação continuada, em especial, no uso das TDIC, além de inferir sobre a importância de um ensino centralizado no estudante, conforme os preceitos das metodologias ativas (BERBEL, 2011; DIESEL et al., 2017; LEITE, 2020).

Em relação aos 78 professores que responderam que não utilizaram alguma tecnologia no ensino (Questão 10), foi solicitado a opinião deles se acham que o uso faria diferença em sua prática pedagógica (Questão 12). Alguns professores se limitaram a dizer que "Sim" (11,5\%), outros afirmaram que "não" (14,1\%), ambos os casos sem apresentarem alguma justificativa. Dos que responderam sim e comentaram (74,4\%) apresenta-se algumas das respostas: "Sim, acho que poderia ser interessante como uma forma de trazer o estudante pra sala de aula e se interessar mais pelo conteúdo" (P917), "Acredito que faria sim diferença, porém, muitas vezes as escolas não tem os materiais necessários, pois nem sempre 0 estudante tem condições de acompanhar determinadas atividades digitais (falta de aparelho adequado e até de internet em suas casas)" (P14) e

Creio que Sim. Possibilita que o aluno adquira uma maior capacidade crítica diante dos desafios propostos. Tornando-se mais ativo e mais envolvido com a aprendizagem. Promovendo uma mudança de sentido e significado e portanto uma mudança de postura dentro do cenário sociocultural que 0 estudante se encontra (P232).

Ao serem questionados se "Você já ouviu falar em Metodologias Ativas?" (Questão 13), 0 Gráfico 2 apresenta os resultados obtidos. 
Gráfico 2 - Conhecimento sobre as Metodologias Ativas.

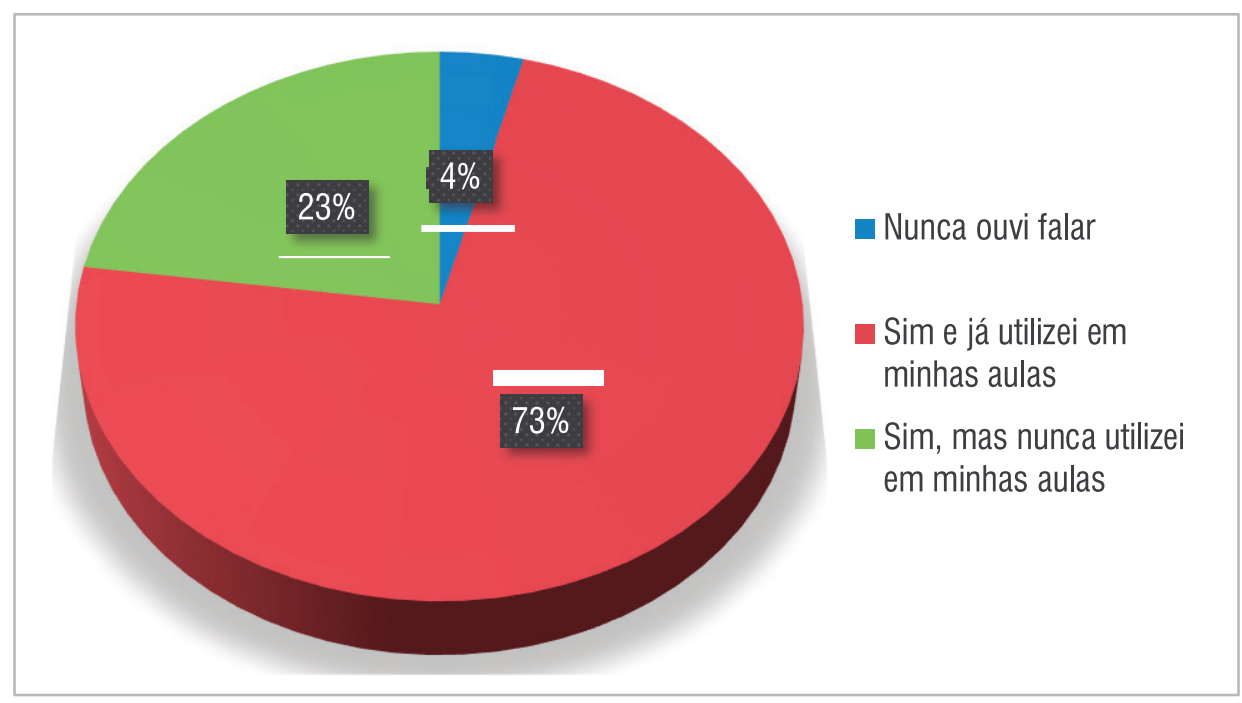

Fonte: Elaborado pelo autor.

Como descrito no Gráfico 2, a maioria dos professores (96\%) informaram já conhecerem as metodologias ativas, tal dado é importante uma vez que as metodologias ativas têm sido utilizadas em diversas práticas pedagógicas (PAIVA et al., 2016; LEITE, 2020). Segundo Leite (2020, p. 6), as metodologias ativas "são estratégias que colocam os estudantes como principais agentes de seu aprendizado". Outro ponto importante dessas respostas é o fato de que cerca de $73 \%$ dos professores já utilizaram alguma metodologia ativa em sua prática docente.

Ao serem questionados quais metodologias ativas eles conhecem (Questão 14), das 18 metodologias ativas indicadas no questionário investigativo, a aprendizagem baseada em problemas foi a que os professores informaram mais conhecer $(70,9 \%)$, seguido da aprendizagem baseada em projetos $(64,4 \%$ ) e 0 Estudo de Caso (método do caso) (58,2\%). A aprendizagem baseada em problemas é um processo de resolução de problemas (reais) que coloca a ênfase na aprendizagem centrada no estudante, isto é, tem o problema como elemento motivador do estudo e integrador do conhecimento (BENDER, 2014). Já a aprendizagem baseada em projetos é caracterizada pelo uso de projetos realistas e considerados autênticos que são baseados em uma questão, tarefa ou problema altamente motivador e envolvente, para ensinar conteúdos acadêmicos aos estudantes no contexto do trabalho cooperativo para a resolução de problemas (BENDER, 2014). 0 Estudo de caso (método do caso) é uma metodologia de ensino em que os estudantes discutem e apresentam soluções para os casos propostos em uma prática pedagógica (MATTAR, 2017). Ela se diferencia do estudo de caso (Case study) que é uma metodologia de pesquisa.

Por outro lado, considerando-se o modelo do Ensino Híbrido como um único tipo de metodologia ativa, em que as estratégias seriam o modelo de rotação, sala de aula invertida etc. (SILVA; SILVA NETO; LEITE, 2021), este modelo apresentaria maior número de ciência dos professores, cerca de 91\%. Leite (2020), destaca que o ensino híbrido é considerado qualquer programa educacional formal 
no qual um estudante constrói sua aprendizagem, pelo menos uma parte, por meio do ensino on-line em que o mesmo tenha controle de algum elemento (tempo, lugar ou ritmo). Existem quatro tipos de modelos de ensino híbrido: Rotação (Rotações por estações; Laboratório rotacional; Sala de aula invertida; Rotação individual); Flex; À la Carte; Virtual Enriquecido (SILVA; SILVA NETO; LEITE, 2021). Atividades utilizando o ensino híbrido per si apresentam em sua essência a incorporação das tecnologias digitais às metodologias ativas. Apenas 3,5\% dos participantes informaram não conhecerem nenhuma metodologia ativa apresentada no questionário investigativo.

A Tabela 2 descreve os resultados obtidos na Questão 14, informando o número de respostas para cada metodologia ativa (considerando que era possível ao participante escolher mais de uma resposta) e o respectivo percentual de escolha.

Tabela 2 - Metodologias Ativas conhecidas pelos professores.

\begin{tabular}{lcc}
\hline Metodologia Ativa & Respostas & $\%$ \\
\hline Aprendizagem Baseada em Problemas & 672 & $70,9 \%$ \\
\hline Aprendizagem Baseada em Projetos & 612 & $64,6 \%$ \\
\hline Aprendizagem Baseada em Equipes & 274 & $28,9 \%$ \\
\hline Aprendizagem Baseada em Games & 280 & $29,5 \%$ \\
\hline Aprendizagem Maker & 162 & $17,1 \%$ \\
\hline Aprendizagem Personalizada & 78 & $8,2 \%$ \\
\hline Estudo de Caso (Método do Caso) & 552 & $58,2 \%$ \\
\hline Gamificação & 358 & $37,8 \%$ \\
\hline Ensino Híbrido (Blended Learning) & 230 & $24,3 \%$ \\
\hline Ensino Híbrido: Rotação por estações & 168 & $17,7 \%$ \\
\hline Ensino Híbrido: Sala de Aula Invertida & 464 & $48,9 \%$ \\
\hline Instrução por Pares (Peer Instruction) & 184 & $19,4 \%$ \\
\hline Ensino sob Medida (Just-in-time Teaching) & 44 & $4,6 \%$ \\
\hline Design Thinking & 152 & $16 \%$ \\
\hline Pensamento Compartilhado em Pares (Think Pair Share) & 64 & $6,8 \%$ \\
\hline Realidade Virtual/Aumentada & 242 & $25,5 \%$ \\
\hline PoGIL (Process Oriented Guided Inquiry Learning) & 130 & $13,7 \%$ \\
\hline Entrevistas em três etapas (Three step interviews) & 30 & $3,2 \%$ \\
\hline Nenhuma & 33 & $3,5 \%$ \\
\hline
\end{tabular}

Fonte: Elaborado pelo autor.

Em relação aos vinte e três aplicativos indicados no questionário foi solicitado que os participantes informassem qual(is) eles acreditam que podem ser utilizados com alguma metodologia ativa (Questão 15) ou qual(is) eles não conhecem (Questão 16). As respostas são descritas na Tabela 3 (em ambas questões era possível ao participante escolher mais de uma resposta). 
Tabela 3 - Aplicativos que podem ser utilizados em uma Aprendizagem Tecnológica Ativa.

\begin{tabular}{|c|c|c|}
\hline Aplicativos & Podem ser utilizados & Não conhecem \\
\hline Kahoot! (https://kahoot.com) & $51,5 \%$ & 47,3 \\
\hline Powtoon (www.powtoon.com) & $13,1 \%$ & 68,1 \\
\hline Edpuzzle (https://edpuzzle.com) & $8 \%$ & $69 \%$ \\
\hline Quizizz (https://quizizz.com) & $55,7 \%$ & $32,5 \%$ \\
\hline Edmodo (https://new.edmodo.com) & $15 \%$ & $61 \%$ \\
\hline Canva (www.canva.com) & $33,1 \%$ & $44,5 \%$ \\
\hline Slido (www.sli.do) & $3,8 \%$ & $74,3 \%$ \\
\hline Plickers (https://plickers.com) & $20,7 \%$ & $60,8 \%$ \\
\hline Google for education (https://edu.google.com) & $75,7 \%$ & $16 \%$ \\
\hline Zoom (https://zoom.us) & $45,6 \%$ & $26,8 \%$ \\
\hline Mentimeter (www.mentimeter.com) & $17,7 \%$ & $57 \%$ \\
\hline Teams (www.microsoft.com/pt-br/microsoft-teams/log-in) & $16 \%$ & $55,5 \%$ \\
\hline Socrative (www.socrative.com) & $17,7 \%$ & $59,7 \%$ \\
\hline Mind Meister (www.mindmeister.com) & $7,6 \%$ & $63,7 \%$ \\
\hline Nearpod (https://nearpod.com) & $2,3 \%$ & $71,3 \%$ \\
\hline Evernote (https://evernote.com) & $10,5 \%$ & $53,2 \%$ \\
\hline LightBot (https://lightbot.com) & $2,7 \%$ & $73,4 \%$ \\
\hline Jamboard (https://edu.google.com/intl/pt-BR/products/jamboard) & $4,6 \%$ & $70,3 \%$ \\
\hline Poll Everywhere (www.polleverywhere.com) & $2,3 \%$ & $73,8 \%$ \\
\hline Vevox (www.vevox.com) & $2,5 \%$ & $74,1 \%$ \\
\hline ClassDojo (www.classdojo.com) & $3,4 \%$ & $68,4 \%$ \\
\hline LiveBoard (https://liveboard.online) & $4,9 \%$ & $68,6 \%$ \\
\hline Padlet (https://padlet.com) & $10,1 \%$ & $64,6 \%$ \\
\hline Nenhum App & $2,3 \%$ & - \\
\hline Conheço todos & - & $4 \%$ \\
\hline
\end{tabular}

Fonte: Elaborado pelo autor.

Os dados da Tabela 3, mostram que os aplicativos do Google for education (Google Classroom, Google Documents, Google Forms, Google Translate, Google Keep etc.) são os mais conhecidos pelos participantes. Segundo Grillo e Ahlert (2018, p. 221), o Google for Education "é um serviço do Google que fornece versões personalizáveis de vários aplicativos", desse modo foi considerado nesta pesquisa utilizar o pacote de aplicativos da Google como uma opção de escolha, ao invés de ter que separar os diversos aplicativos desenvolvidos pela empresa.

0 Quizizz foi apontado pelos professores como o segundo aplicativo $(55,7 \%)$ e o Kahoot! $(51,7 \%)$ como o terceiro que podem ser utilizados junto com uma estratégia envolvendo metodologias ativas e 0 Sli.do foi considerado como o menos conhecido (74,3\%). Todos os aplicativos visualizados no questionário foram selecionados pelo menos uma vez por algum professor (uns com maior número de indicações e outros com menor número), revelando que, na concepção destes participantes, todos podem ser utilizados dentro de uma estratégia com as metodologias ativas (fazendo uso das tecnologias digitais), possibilitando uma aprendizagem tecnológica ativa (LEITE, 2018). Em contra partida, alguns aplicativos apresentaram percentual superior a $70 \%$ de desconhecimento dos 
professores, são eles: Vevox (74,1\%), Poll Everywhere (73,8\%), LightBot (73,4\%), Nearpod (71,3\%), Jamboard (70,3\%).

Dos aplicativos mais conhecidos pelos professores (Google for education, Quizizz e Kahoot!), depreende-se que a utilização destes na educação é possível por meio da ATA, em que, por exemplo, o professor pode escolher o Kahoot! para discutir um determinado conteúdo (Pilares: Papel docente e Suporte das Tecnologias) 0 auxiliando no acompanhamento da aprendizagem dos estudantes (Pilar: Avaliação). 0 estudante faz uso do Kahoot! durante a atividade (Pilar: Suporte das tecnologias), podendo utilizar outros recursos para sua aprendizagem (Pilar: Protagonismo do estudante) possibilitando a estes aprenderem durante a atividade proposta (Pilar: Aprendizagem). Ademais, segundo Licorish, Owen, Daniel e George (2018), o uso do aplicativo Kahoot! enriquece a qualidade da aprendizagem dos estudantes em sala de aula, contribuindo para uma maior dinâmica, envolvimento, motivação e melhoria da experiência de aprendizagem. Nesse sentido, não apenas o Kahoot!, mas todos os aplicativos mencionados nesta pesquisa podem contribuir para o processo de ensino e aprendizagem, e consequentemente, para uma ATA. Nota-se que a ATA possibilita alternativas para uma aprendizagem ativa, centrada nos estudantes, permitindo que o professor possa acompanhar 0 processo de construção do conhecimento deles (LEITE, 2020).

Ao serem solicitados para informarem "Quais aplicativos você conhece e que podem ser utilizados dentro de uma abordagem baseada em metodologias ativas e não foram citados aqui?" (Questão 17), a maioria dos professores (86,7\%) responderam que os que eles conheciam já tinham sido apresentados, porém 13,3\% compartilharam outros 50 aplicativos, os dez mais citados por eles foram: trello, Quizlet, hand talk - Acessibilidade em Libras, Pixton, Goconqr, Tik Tok, Flipsnack, Draw.io, storyjam e PhET. Destes apontados pelos professores, muitos já foram utilizados no contexto educacional, por exemplo, o Hand Talk (COLLING; BOSCARIOLI, 2014), a Pixton (LEITE, 2017b), o Quizlet (SANOSI, 2018) e o Tik Tok (LIU; YANG; LI, 2020). Ressalta-se que na escolha dos recursos tecnológicos, conforme o pilar suporte das tecnologias da ATA, é possível aos professores criarem novos caminhos para a aprendizagem de seus estudantes e que não há um único aplicativo que pode ser utilizado.

No que diz respeito a Questão 18 ("Indique três aplicativos que você considera importante de ser utilizado na Educação"), 684 participantes elencaram três aplicativos que eles consideram possíveis de serem utilizados em sala de aula (ou que já utilizaram). Os três aplicativos com maior número de indicação foram: Google for education (24,2\%), Kahoot! (21,5\%) e o Quizizz (9,3\%), lembrando que a plataforma Google for education contempla diversos aplicativos em sua G-suite (Google sala de aula, Google Documentos, Google Formulários, Google Tradutor, Keep, Hangout, Google Sites, Google maps etc). Nesse contexto, é importante destacar que em relação aos aplicativos da Google for education inúmeros trabalhos têm apresentado as contribuições destes na Educação, por exemplo, Grillo e Ahlert (2018), investigaram as percepções de 42 professores sobre este recurso e apontam que as principais vantagens reconhecidas pelos professores na utilização dos aplicativos da Google são 0 dinamismo, inovação e criatividade nas aulas. Em uma pesquisa comparando o Kahoot! e 0 Quizizz, Göksüna e Gürsoy (2019), afirmam que atividades com 0 aplicativo Kahoot! apresentam um impacto mais positivo no desempenho acadêmico e no envolvimento dos estudantes quando comparadas as atividades com 0 Quizizz.

Por fim, a última pergunta (Questão 19), buscava ouvir os participantes em relação a pesquisa. Foram deixados 247 comentários, boa parte deles parabenizando pela iniciativa e pelo foco da pesquisa e agradecendo 0 fato de que muitas metodologias ativas e/ou aplicativos apresentados não 
eram conhecidos por eles, sendo "[foi] uma oportunidade valiosa em conhecer essas metodologias" (P18) e que "gostaria de saber mais" (P33). Outros destacaram que "As metodologias ativas precisam ser bem divulgadas para que sejam utilizadas de forma expressiva em sala de aula. [...] É preciso que a hibridização metodológica seja bem divulgadas para que todos se beneficiem das tecnologias em sala de aula" (P539) e que as "metodologias ativas são suportes interessantes e empolgantes e através dessa pesquisa será possível incentivar os profissionais da Educação para se envolverem no mundo contemporâneo" (P841). Ademais, os professores solicitaram o compartilhamento da pesquisa.

\section{CONSIDERAÇÕES FINAIS}

0 foco desse estudo foi levantar informações dos professores sobre quais metodologias ativas e tecnologias digitais (aplicativos) são conhecidas por eles e quais aplicativos podem ser utilizados com alguma metodologia ativa na educação, observando as possibilidades de relação com o modelo da aprendizagem tecnológica ativa.

0 que se pode conjecturar desta pesquisa é que os professores demonstraram conhecer boa parte das 18 metodologias ativas apresentadas, com destaque para a Aprendizagem Baseada em Problemas e Aprendizagem Baseada em Projetos (apontadas como as mais conhecidas). Poucos professores responderam não conhecerem nenhum tipo de metodologia ativa. Para estes, se mostra importante que nos cursos de formação continuada sejam enfatizadas discussões sobre as metodologias ativas de modo a possibilitar que os professores possam conhecê-las e, posteriormente, aplicá-las em suas práticas pedagógicas.

Em relação aos 23 aplicativos, os professores revelaram que o pacote de aplicativos da Google for education (Google Classroom, Google Documents, Google Forms, Google Translate, Google Keep etc.), o Quizizz e o Kahoot! são os mais conhecidos por eles. Além disso, estes três aplicativos também foram apontados pelos professores como os mais indicados para serem utilizados dentro de uma estratégia baseada no uso de metodologias ativas (consequentemente por meio do modelo da aprendizagem tecnológica ativa) no processo de ensino e aprendizagem.

Por fim, é importante repensar o ensino, 0 ambiente educacional (escolas e universidades) e a prática pedagógica dos professores, a partir do desenvolvimento de pesquisas que tratem desses temas envolvendo 0 uso das tecnologias digitais e das metodologias ativas (a Aprendizagem Tecnológica Ativa).

\section{REFERÊNCIAS}

ARAUJO, T. 0. Tecnologias móveis na educação: reflexões e práticas. LínguaTec, v. 5, n. 1, p. 59-80, 2020.

BELLONI, M. L. Tecnologia e formação de professores: Rumo a uma pedagogia pós-moderna?. Educação \& Sociedade, v. 19, n. 65 , p. $143-162,1998$.

BENDER, W. N. Aprendizagem baseada em projetos: Educação diferenciada para o século XXI. Porto Alegre: Penso, 2014.

BERBEL, N. A. N. As metodologias ativas e a promoção da autonomia de estudantes. Semina: Ciências Sociais e Humanas, v. 32, n. 1, p. 25-40, 2011. 
BOTTENTUIT JUNIOR, J. B. Do computador ao tablet: Vantagens pedagógicas na utilização de dispositivos móveis na educação. Revista educaonline, v. 6, n. 1, p. 125-149, 2012.

CARMO, V. 0 uso de questionários em trabalhos científicos. 2013. Disponível em: https://bit.ly/3zsQziy. Acesso em: 12 fev. 2021.

COLLING, J. P.; BOSCARIOLI, C. Avaliação de tecnologias de tradução Português-Libras visando o uso no ensino de crianças surdas. RENOTE-Revista Novas Tecnologias na Educação, v. 12, n. 2, p. 1-10, 2014.

CóSSIO, M. F. A nova gestão pública: alguns impactos nas políticas educacionais e na formação de professores. Educação, v. 41, n. 1, p. 66-73, 2018.

DIESEL, A.; BALDEZ, A. L. S.; MARTINS, S. N. Os princípios das metodologias ativas de ensino: uma abordagem teórica. Revista Thema, v. 14, n. 1, p. 268-288, 2017.

GIL, A. C. Como elaborar projetos de pesquisa. São Paulo: Atlas, 2017.

GÖKSÜN, D. 0.; GÜRSOY, G. Comparing success and engagement in gamified learning experiences via Kahoot and Quizizz. Computers \& Education, v. 135, p. 15-29, 2019.

GRILLO, M. I. H.; AHLERT, E. M. Utilização dos recursos do programa Google for Education nas práticas docentes dos professores do Centro De Educação Profissional da Univates. Revista Destaques Acadêmicos, v. 10, n. 4, p. 217-231, 2018.

GUEDES, I. A. C.; SANCHEZ, L. B. A formação docente para a educação profissional técnica e sua influência na atuação dos professores do Instituto Federal do Amapá-Campus Macapá: um estudo de caso. HOLOS, v. 7, p. 238-252, 2017.

JÚNIOR, C. P. Formação Docente frente às Novas Tecnologias: desafios e possibilidades. InterMeio: Revista do Programa de Pós-Graduação em Educação-UFMS, v. 24, n. 47, p. 189-210, 2018.

LEITE, B. Aprendizagem tecnológica ativa. Revista internacional de educação superior, v. 4, n. 3, p. 580-609, 2018.

LEITE, B. S. M-Learning: 0 uso de dispositivos móveis como ferramenta didática no Ensino de Química. Revista Brasileira de Informática na Educação, v. 22, n. 3, p. 55-68, 2014.

LEITE, B. S. Gamificando as aulas de química: uma análise prospectiva das propostas de licenciandos em química. RENOTE-Revista Novas Tecnologias na Educação, v. 15, n. 2, p. 1-10, 2017a.

LEITE, B. S. Histórias em quadrinhos e ensino de química: propostas de licenciandos para uma atividade lúdica. Revista Eletrônica Ludus Scientiae, v. 1, n. 1, p. 58-74, 2017b.

LEITE, B. S. Estudo do corpus latente da internet sobre as metodologias ativas e tecnologias digitais no ensino das Ciências. Pesquisa e Ensino, v. 1, e202012, 2020.

LICORISH, S. A.; OWEN, H. E.; DANIEL, B.; GEORGE, J. L. Students' perception of Kahoot!'s influence on teaching and learning. Research and Practice in Technology Enhanced Learning, v. 13, n. 1, p. 1-23, 2018. 
LIU, J.; YANG, W.; LI, S. The Influence of Short Video on City Image Dissemination in the New Media Era -Taking Tik Tok as an Example. Education Research Frontier, v. 10, n. 1, p. 6-10, 2020.

LUCENA, S. Culturas digitais e tecnologias móveis na educação. Educar em Revista, n. 59, p. 277-290, 2016.

MATTAR, J. Metodologias ativas: para a educação presencial, blended e a distância. São Paulo: Artesanato Educacional, 2017.

PAIVA, M. R. F.; PARENTE, J. R. F.; BRANDÃO, I. R.; QUEIROZ, A. H. B. Metodologias ativas de ensino-aprendizagem: revisão integrativa. SANARE-Revista de Políticas Públicas, v. 15, n. 2, p. 145-153, 2016.

PRETTO, N. D. L.; PASSOS, M. S. C. Formação ou Capacitação em TIC? Reflexões sobre as Diretrizes da UNESCO. Revista Docência e Cibercultura, v. 1, n. 1, p. 9-32, 2017.

REIS, R. S.; LEITE, B. S.; LEÃO, M. B. C. Apropriação das Tecnologias da Informação e Comunicação no ensino de ciências: uma revisão sistemática da última década (2007-2016). RENOTE-Revista Novas Tecnologias na Educação, v. 15, n. 2, p. 1-10, 2017.

ROCHA, K. M.; BITTAR, M. Uma proposta de formação continuada de professores à luz da abordagem dos conhecimentos pedagógicos tecnológicos do conteúdo. VIDYA, v. 37, n. 1, p. 161-175, 2017.

SANOSI, A. B. The effect of Quizlet on vocabulary acquisition. Asian Journal of Education and e-learning, v. 6, n. 4, p. 71-77, 2018.

SILVA NETO, S. L.; LEITE, B. S. A concepção de um professor designer: analisando um caso no curso de licenciatura em Química. Revista de Educação, Ciências e Matemática, v. 10, n. 2, p. 147-156, 2020.

SILVA, B. R. F.; SILVA NETO, S. L.; LEITE, B. S. Sala de aula invertida no ensino de química orgânica: um estudo de caso. Química Nova, v. 44, 2021.

RECEBIDO EM: 22 mar. 2021

CONCLUÍDO EM: 14 jun. 2021 